\title{
The 2012 Pianura Padana Emiliana seimic sequence: locations, moment tensors and magnitudes
}

\author{
Laura Scognamiglio ${ }^{\star}, 1$, Lucia Margheriti ${ }^{1}$, Francesco Mariano Mele ${ }^{1}$, Elisa Tinti $^{2}$, Andrea Bono ${ }^{1}$, \\ Pasquale De Gori ${ }^{1}$, Valentino Lauciani ${ }^{1}$, Francesco Pio Lucente ${ }^{1}$, Alfonso Giovanni Mandiello ${ }^{1}$, \\ Carlo Marcocci $^{1}$, Salvatore Mazza ${ }^{1}$, Stefano Pintore ${ }^{1}$, Matteo Quintiliani ${ }^{1}$
}

\author{
${ }^{1}$ Istituto Nazionale di Geofisica e Vulcanologia, Centro Nazionale Terremoti, Roma, Italy \\ 2 Istituto Nazionale di Geofisica e Vulcanologia, Sezione Roma 1, Roma, Italy
}

\begin{abstract}
Article history
Received July 24, 2012; accepted August 10, 2012.

Subject classification:

Seismology, Earthquake source and dynamics, Surveys, measurements, and monitoring, Waves and wave analysis.
\end{abstract}

\section{Introduction}

On May 20, 2012 (02:03:53 UTC), an $\mathrm{M}_{\mathrm{W}} 5.86\left(\mathrm{M}_{\mathrm{L}}\right.$ 5.9) earthquake struck the Pianura Padana Emiliana region (northern Italy), causing five deaths and damage to several villages and to the towns of Ferrara and Modena. The mainshock was preceded, three hours earlier, by a $\mathrm{M}_{\mathrm{W}} 3.98\left(\mathrm{M}_{\mathrm{L}} 4.1\right)$ foreshock, which almost co-located with the main event. After the main event, the seismic sequence included six earthquakes with magnitudes $>5.0$. The biggest aftershock was located about $12 \mathrm{~km}$ west of the first mainshock, and was a $\mathrm{M}_{\mathrm{W}} 5.66\left(\mathrm{M}_{\mathrm{L}}\right.$ 5.8) earthquake that occurred on May 29, 2012 (07:00:03 UTC); this can be considered as a second mainshock. After this event, the official death toll of the seismic sequence was 17 people. Moreover, there had been severe damage to the economy of the region and there were 13,000 homeless.

This region is on the outer front of the northern Apennines, and it has been characterized by relatively low seismic hazard [Seismic Hazard Map of Italy - MPS04; MPS Working Group 2004]. In the three months preceding May 19, 2012, this area experienced a few events with maximum magnitude $M_{L} 2.9$, and since 2005, this area has been characterized by relatively moderate seismicity, which has been mainly concentrated along the Apennine front that delimits the southern Po Plain [ISIDe DataBase; Mele et al. 2007]. The last large historical earthquakes in the studied area were: the November 17, 1570, $\mathrm{M}_{\mathrm{W}} 5.48$ Ferrara event, and the March 17, 1574, event that produced damage in Finale Emilia $\left(\mathrm{M}_{\mathrm{W}} 4.72\right)$ [CPTI11 2011; Rovida et al. 2011].

The northern Apennines frontal thrust system is composed of a pile of NE-verging tectonic units that have developed as a consequence of the Cenozoic collision between the European plate and the Adria plate [Boccaletti et al. 2011]. The geometries of the thrusts buried below the Po
Plain sediments have been studied through seismic reflection profiles [Pieri and Groppi 1981, Ori and Friend 1984], and they show three major curved thrust fronts: the Monferrato, Emilia, and Ferrara-Romagna Arcs. Active NE-SW shortening along the outer Apennines front has been documented by: global positioning system data, that show an average horizontal shortening of approximately $1 \mathrm{~mm} / \mathrm{y}$ [Zerbini et al. 2006, Devoti et al. 2010]; borehole breakouts [Montone and Mariucci 1999, Montone et al. 2004]; and centroid moment tensor solutions [Pondrelli et al. 2006].

This activated fault system is elongated in the East-West direction (almost $50 \mathrm{~km}$ long), and centered on the village of Mirandola, the epicenter of the mainshock. In this study, we have analyzed data that arrived in real time at the Istituto Nazionale di Geofisica e Vulcanologia (INGV; National Institute of Geophysics and Volcanology) seismic monitoring center from permanent (Italian National Seismic Network; INSN) and temporary [Moretti et al. 2012, this volume] seismic stations, to describe the spatial and temporal evolution of the seismic sequence and the source parameters for earthquakes with $M_{L} \geq 4.0$, and to perform an accurate study for $\mathrm{M}_{\mathrm{L}}$ calibration.

\section{Temporal evolution of the sequence}

The May 20, 2012, earthquake was preceded by five foreshocks, the larger of which was a $\mathrm{M}_{\mathrm{L}} 4.1$ event that occurred on May 19, 2012, at 23:13 UTC. Half an hour after the mainshock struck, the monitoring system of the INGV [Amato and Mele 2008] released its parameters: $M_{L} 5.9$, origin time 02:03:52.0 UTC (04:03 local time), latitude $44.89^{\circ} \mathrm{N}$, longitude $11.23^{\circ} \mathrm{E}$, and depth $6.3 \mathrm{~km}$. The earthquake nucleated below the Po Valley, in the Emilia region, not far from the town of Ferrara. It activated an E-W trending thrust fault that was about $15 \mathrm{~km}$ long. It was followed at 02:07 UTC by a 
a)

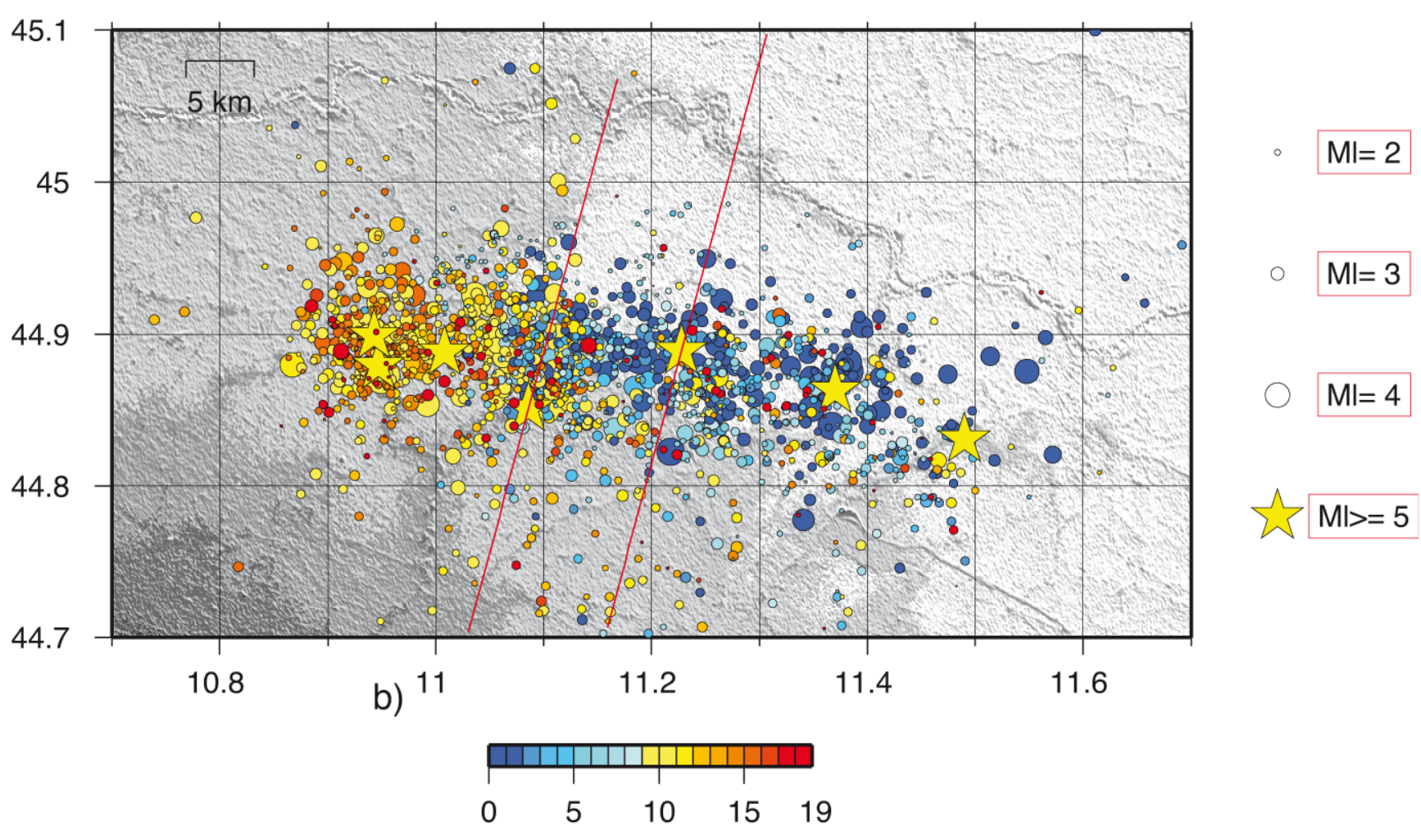

days from mainshock (May 20 2012 )

b)

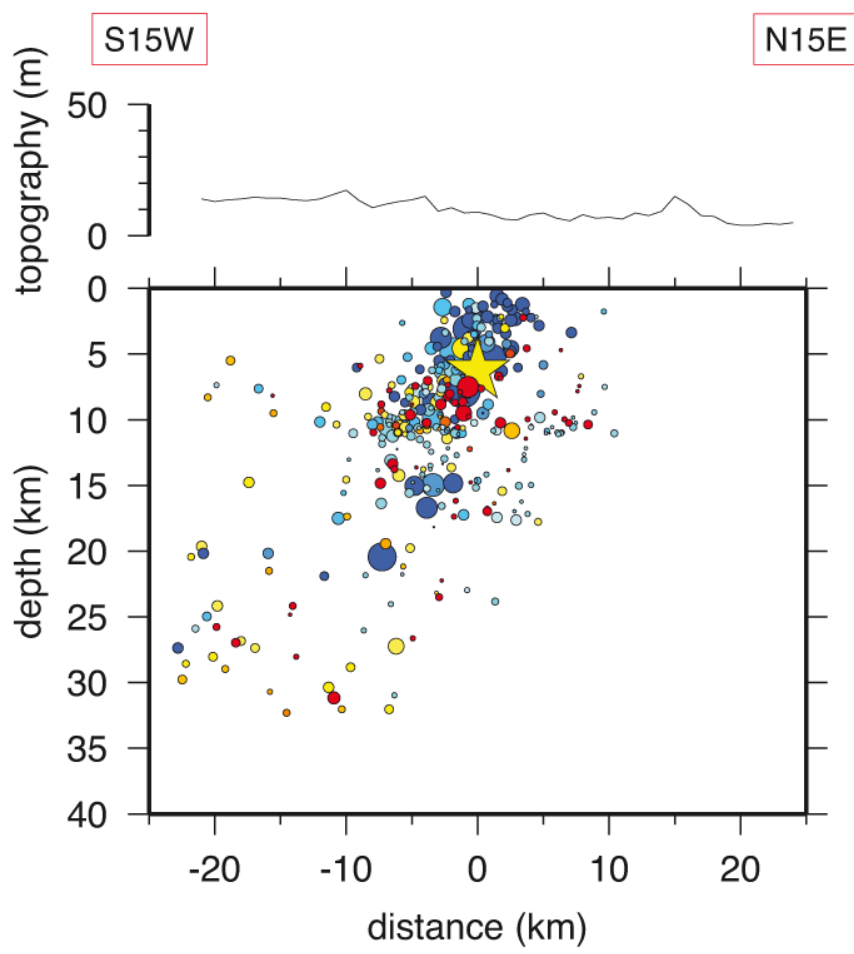

c)

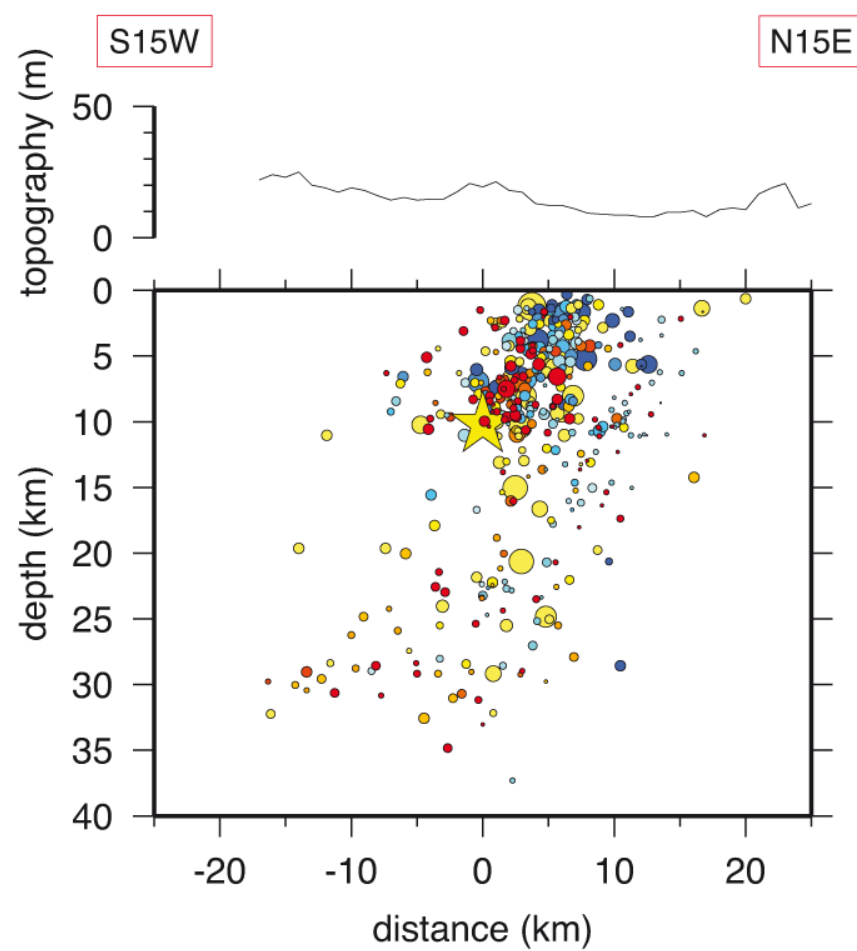

Figure 1. (a) Map of the seismicity for the period May 20 to June 21, 2012, with the color code indicating the time after the main event. Red lines, traces of the vertical sections shown in the bottom of the figure. (b) Vertical section passing through the hypocenter of the May 29, 2012, mainshock, which shows an activated fault system that is clearly dipping to the South. (c) Vertical section across the May 20, 2012, hypocenter shows a relatively complicated activated fault system. The lines above the panels show the surface topography with a $\times 200$ vertical exaggeration. 


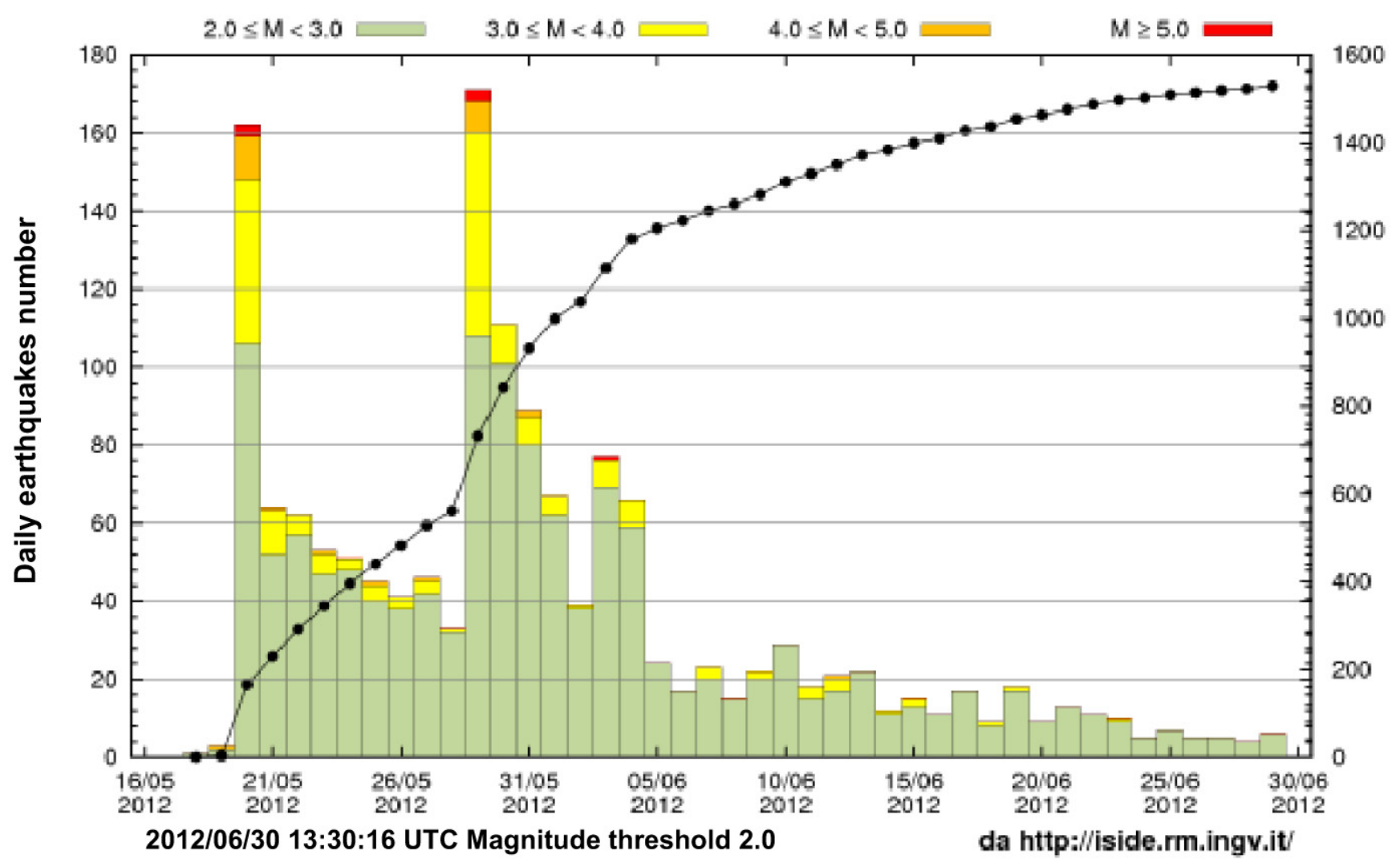

Figure 2. The pattern of seismicity with time (from http://terremoti.ingv.it/it/ultimi-eventi/842-terremoti-in-pianura-padana-emiliana.html). indicating the number of events per day, their magnitude and the cumulative number of events with time.

$M_{L} 5.1$ event, and then later by a second $M_{L} 5.1$ earthquake, at 13:18 UTC, both of which were located to the east of the mainshock (Figure 1). The activated structures dip to the south (Figure 1c). In the following three days, the area was shaken by 68 earthquakes with magnitudes $>3$, including 13 shocks with $M_{L} \geq 4.0$. Another 240 minor events were recorded and located by the seismic stations during this time interval [data source: 2005-2012 ISIDe; Mele et al. 2007]. The seismicity rate in the following days remained high (Figure 2), with events spread over a relatively large area (ca. $40 \mathrm{~km}$ long, E-W, and ca. $15 \mathrm{~km}$ wide, N-S, from the last 5.1 event to the east, to about $10 \mathrm{~km}$ west of the mainshock; Figure 1).

On May 29, 2012, the second-largest shock, $\mathrm{M}_{\mathrm{L}} 5.8$, struck at 07:00 UTC: this event was located at latitude $44.85^{\circ} \mathrm{N}$, longitude $11.09^{\circ} \mathrm{E}$, and depth $10.2 \mathrm{~km}$. This earthquake ruptured an adjacent thrust fault segment, located to the west. During the following days, hundreds of aftershocks occurred, including $\mathrm{M}_{\mathrm{L}} 5.2$ and $\mathrm{M}_{\mathrm{L}} 5.3$ shocks at 10:55 UTC and 11:00 UTC on May 29, 2012, respectively. The seismicity then spread along a more than $50-\mathrm{km}$-long fault system. Looking at the western cross-section (Figure 1b), the activated structure appears quite complex. Again a magnitude 5.1 earthquake struck at the western edge of the activated fault system on June 3, 2012, at 19:20 UTC. In the following days of June, there was an Omori-like temporal decay of the seismicity: a progressive decrease in the seismic rate and seismic moment release.
The locations reported in ISIDe are reported by the seismologists who are on duty $24 \mathrm{~h}$ a day at the INGV seismic monitoring center, with a $1 \mathrm{D}$ velocity model as input. It is interesting to note that the total number of events located by the INGV monitoring system in the first month after the mainshock was significantly lower than for the L'Aquila 2009 seismic sequence (1192 located in Emilia versus 9312 in L'Aquila). This difference disappears if we consider only events with magnitudes $>3$ (215 in Emilia versus 220 in L'Aquila). The cause of this difference appears to be related to the high level of anthropogenic noise in the Po Plain, which makes it more difficult to record and locate small-magnitude events [Marzorati et al. 2012, this volume], even after the installation of a dense temporary network that was deployed in the epicentral area [Moretti et al. 2012, this volume]. Moreover, the presence of soft sediments with strongly variable thicknesses below the seismic stations influences the location and magnitude determinations. Future studies that use an accurate $3 \mathrm{D}$ velocity model for all of the temporary stations deployed after the mainshock, and that consider local site effects, will improve the accuracy of these determinations.

\section{Moment tensor solutions}

Time-domain moment tensor solutions (TDMT) were computed during the seismic sequence using the technique proposed by Dreger and Helmberger [1993], and implemented at the INGV for automatic operations, by Scogna- 


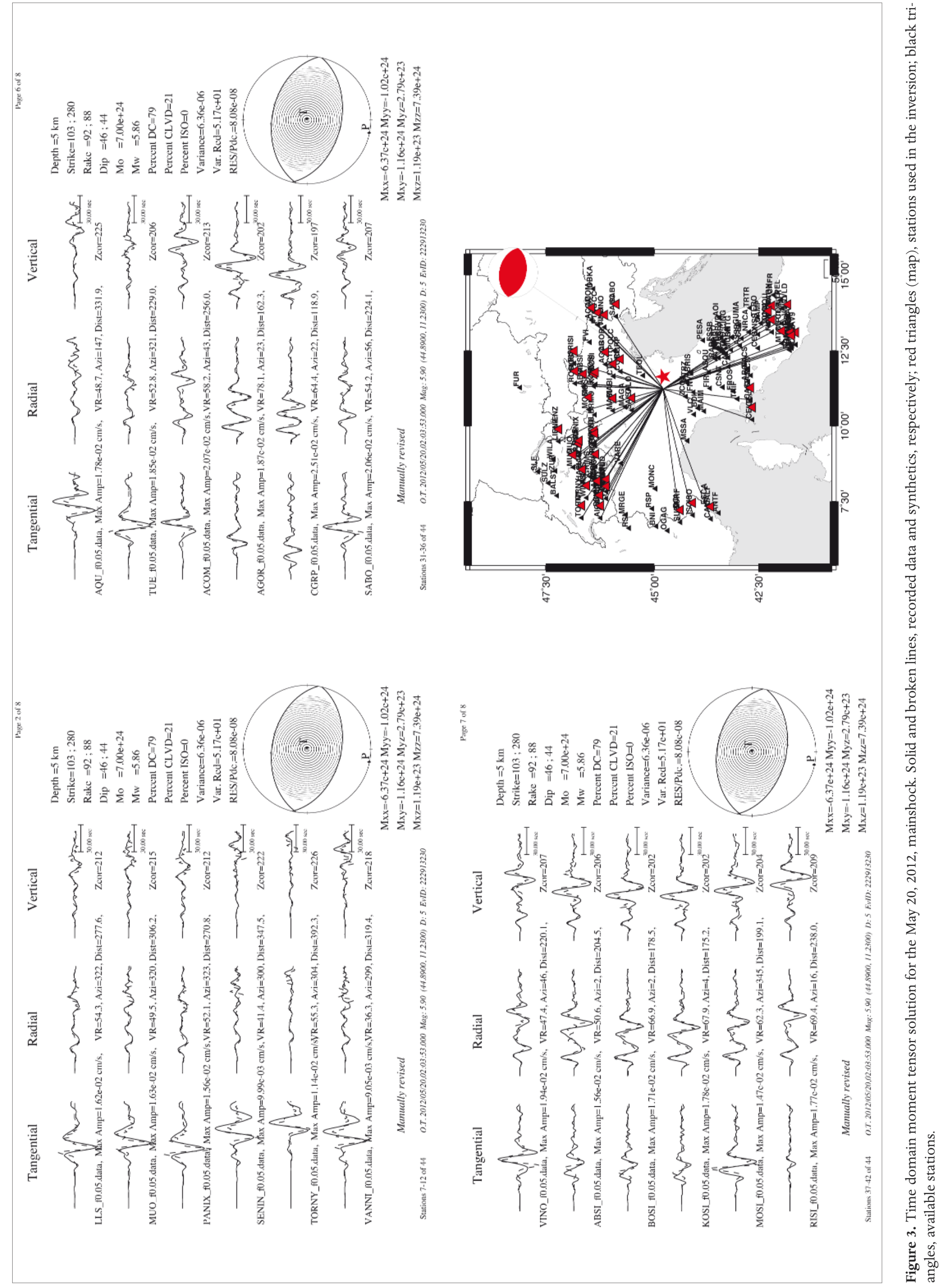


miglio et al. [2009]. The algorithm performs the time-domain full waveform inversion of band-passed ground velocity gathered in real-time by the INSN. The isotropic component is constrained to zero, and the moment tensor solution provides the percentage of double-couple and the compensated linear vector dipole.

Given the set of all of the available stations, the choice of the subset is performed through an original algorithm (written by Matteo Quintiliani, 2012, personal communication), which returns the larger list of stations with the best uniform distribution. The algorithm is based on the graph theory approach and the weighed minimization of the standard deviations among distances of stations from the epicenter and azimuthal angles between adjacent stations.

For the first mainshock (May 20, 2012, 02:03:52 UTC), the automatic solution that was obtained with 64 stations was available on the web page http://cnt.rm.ingv.it/tdmt. html at 03:45 UTC. This solution was characterized by a good waveform fit (variance reduction, $50.5 \%$; double couple, $82 \%$ ) and it featured a thrust fault mechanism and a magnitude $\mathrm{M}_{\mathrm{W}} 5.84$ [see Mazza et al. 2012, this volume]. The reviewed solution (Figure 3 ) shows very similar source parameters and a slightly greater magnitude of $\mathrm{M}_{\mathrm{W}} 5.86$.

The automatic solution of the second-largest shock (May 29, 2012, 07:00:03 UTC) was published after slightly more than $1 \mathrm{~h}$. The automatic and the reviewed moment tensor solutions were very similar.

Among the 32 earthquakes with $\mathrm{M}_{\mathrm{L}} \geq 4.0$ during the May 19, 2012, to May 30, 2012, time period, we were able to determine the source parameters for 19 events (Figure 4). The remaining 13 events were closely preceded or followed by other earthquakes that hindered the inversion, and drastically reduced the signal-to-noise ratio. Most of the fault plane solutions showed a dominant reverse faulting with a

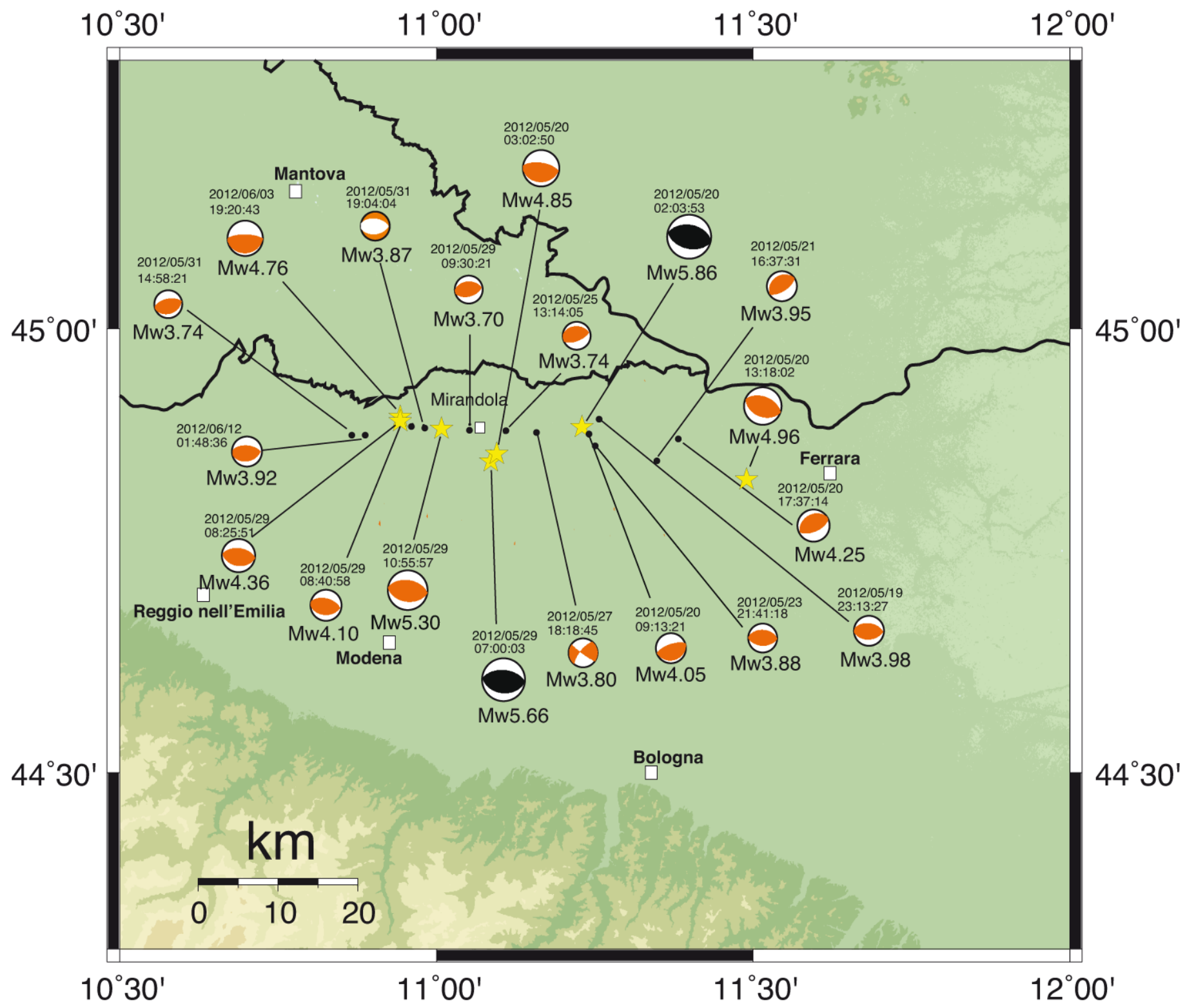

Figure 4. Focal mechanisms of the earthquakes with $\mathrm{M}_{\mathrm{L}} \geq 4.0$, determined using the TDMT technique. Black, the two mainshock mechanisms. 
mainly E-W strike, in agreement with the tectonic setting and the active stress field of the area. However, the May 27, 2012, 18:18:45 UTC, $\mathrm{M}_{\mathrm{L}} 4.0$ earthquake, and the May 31, 2012, 19:04:04 UTC, $M_{L} 4.2$ earthquake showed strike slip and normal fault motion, respectively, which indicated that there might be a mechanism of syn-compressional extension in the thrust-fault-related regimes [Carminati and Valdacca 2010, Boccaletti et al. 2011].

Complete information and the waveform fits are available on the dedicated web page (http:/ / cnt.rm.ingvit/tdmt.html).

\section{Local magnitude $\left(\mathrm{M}_{\mathrm{L}}\right)$ determination}

The Advanced Information and Data Acquisition system for seismology (the AIDA system) is an Earthworm installation that can locate earthquakes and compute their local magnitudes in real time [Mazza et al. 2012]. At each station, the local band magnitude (from short-period or broad-band velocimeters, or accelerometers) is provided by the average of the component magnitudes from both horizontals; the total station magnitude is the mean of the band magnitudes that are available. Finally, the local magnitude of the event is the median of the station magnitudes.

The $\mathrm{M}_{\mathrm{L}}$ magnitude is computed for all of the stations between $10 \mathrm{~km}$ and $600 \mathrm{~km}$ distance from the hypocenter, which were used in the location of the event. The restriction on the minimum distance to $10 \mathrm{~km}$ is necessary to avoid large errors in magnitude due to possible large errors in the depth determination. The AIDA system now applies the distance correction described by Hutton and Boore for California [Hutton and Boore 1987]; we refer to this magnitude as the Hutton Boore magnitude (MLHB). To improve the magnitude evaluations, we tested an attenuation relation for Italy [Gasperini 2002]; we refer to this magnitude as MLG.

\begin{tabular}{cccc}
\hline $\begin{array}{c}\text { Origin Date, Time } \\
\text { (yyyy-mm-dd, hh:min:ss) }\end{array}$ & MLGC & MLHB & TDMT-Mw \\
\hline 2012-05-20, 02:03:52 & 5.90 & 5.87 & 5.9 \\
2012-05-20, 02:07:31 & 5.03 & 5.06 & N.A. \\
2012-05-20, 13:18:02 & 5.19 & 5.11 & 5.0 \\
2012-05-20, 17:37:14 & 4.59 & 4.54 & 4.3 \\
2012-05-29, 07:00:03 & 5.76 & 5.77 & 5.7 \\
2012-05-29, 08:25:51 & 4.52 & 4.50 & 4.4 \\
2012-05-29, 10:55:57 & 5.36 & 5.32 & 5.3 \\
2012-05-29, 11:00:02 & 5.06 & 5.05 & N.A. \\
2012-06-03, 19:20:43 & 4.99 & 5.14 & 4.8 \\
\hline
\end{tabular}

Table 1. Magnitudes of the main earthquakes of the Emilia sequence, computed by at least 10 stations (we did not include the $M_{L} 4.9$ event of May 20, 2012, 03:02:50 UTC, the magnitude of which was computed with less than 10 stations). The reported magnitudes (MLHB) are compared to the values computed in this study (MLGC), and to the $\mathrm{M}_{\mathrm{W}}$ obtained from TDMT.
We analyzed 1574 earthquakes of the seismic sequence from May 18 to June 16, 2012 (51789 synthetic Wood Anderson amplitudes). As a first step, we calculated a new set of MLGs for 726 selected events, with at least 20 observations from stations with at least 10 events each (a subset of 43472 Wood-Anderson single component amplitudes). Using this subset of data, we computed the station corrections for 131 stations (Supplementary Materials).

We then evaluated the MLG again by applying the Gasperini relation and the new station corrections, for all of the 51486 records of 1574 events (first set of data); we refer to these magnitudes as MLGC. We obtained a variance reduction of $66.9 \%$ with respect to the MLHB (Supplementary Table S1) and a reduced dispersion of data at all distances (Supplementary Figure S1).

Figure 5 shows the distribution of the MLHB versus the MLGC. There was good correspondence between the two values for $M_{L}>3.5$, while the Hutton-Boore relation gave greater magnitudes for small earthquakes. An explanation can be found by observing that the $-\log \mathrm{A}_{0}$ function of Hutton-Boore (Figure 6, cyan line) reaches larger values than those of Gasperini at short distances (Figure 6, dark blue line), although it is under the Gasperini curve at distances exceeding $100 \mathrm{~km}$ (Figure 6). In the computation of large events through the Hutton-Boore relation, stations at all distances can be used, and the final magnitude is affected both by the lower part and by the higher part of the Hutton-Boore correction. In the evaluation of small events instead, only stations at a short distance from the hypocenter can contribute to the magnitude computation.

Table 1 shows the MLHB (green panel) and the corresponding TDMT- $\mathrm{M}_{\mathrm{W}}$ (pink panel). The $\mathrm{M}_{\mathrm{L}}$ computed in this study (the MLGCs) are also shown for comparison: the magnitude values of the two main events of April 20 and 29 are very stable, independent of the evaluation method.

\section{Conclusions}

The Emilia 2012 seismic sequence with two main events of $M_{W} 5.86$ and 5.66 activated a thrust fault system about $50 \mathrm{~km}$ long that is buried below the Po Plain alluvial sediments. These earthquakes produced victims and severe damage to the local historic buildings, and to economic activities in the epicentral area. In this preliminary analysis of the seismic sequence, we present and briefly revise the data produced in almost real-time by the INGV monitoring seismic center.

During the first 16 days, the seismic sequence showed migration from the East to the West. The earthquake locations do not allow us to clearly identify the geometries of the activated structures, even if a cross-section through the eastern part of the sequence delineates a south-dipping $45^{\circ}$ plane that is consistent with the moment tensor solution of the first mainshock.

Most of the computed focal mechanism solutions fit 


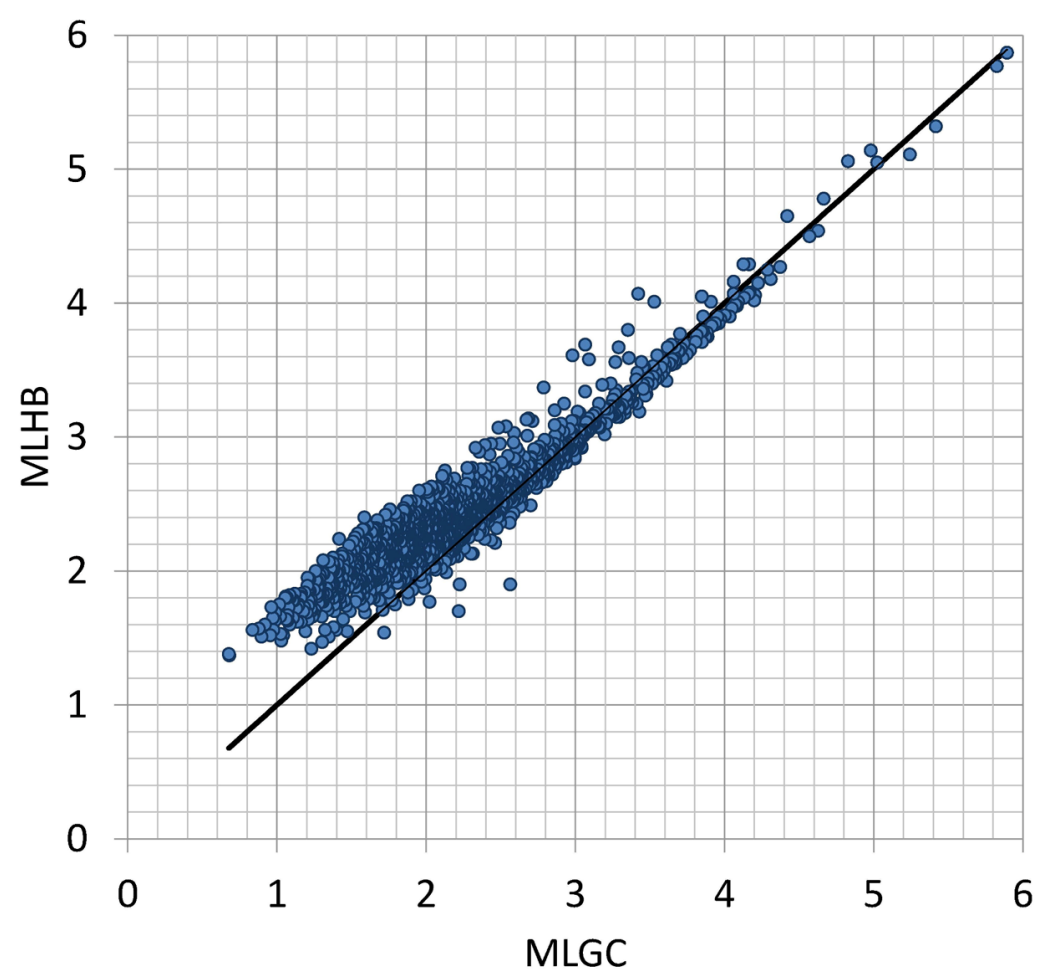

Figure 5. Hutton Boore magnitudes for the Emilia seismic sequence (MLHB) as a function of the same magnitudes computed with the Italian attenuation relation and station corrections (MLGC). There is a good correspondence of the values $>M_{L} 3.5$, while the Hutton Boore relation overestimates the magnitudes of small events, as an average.

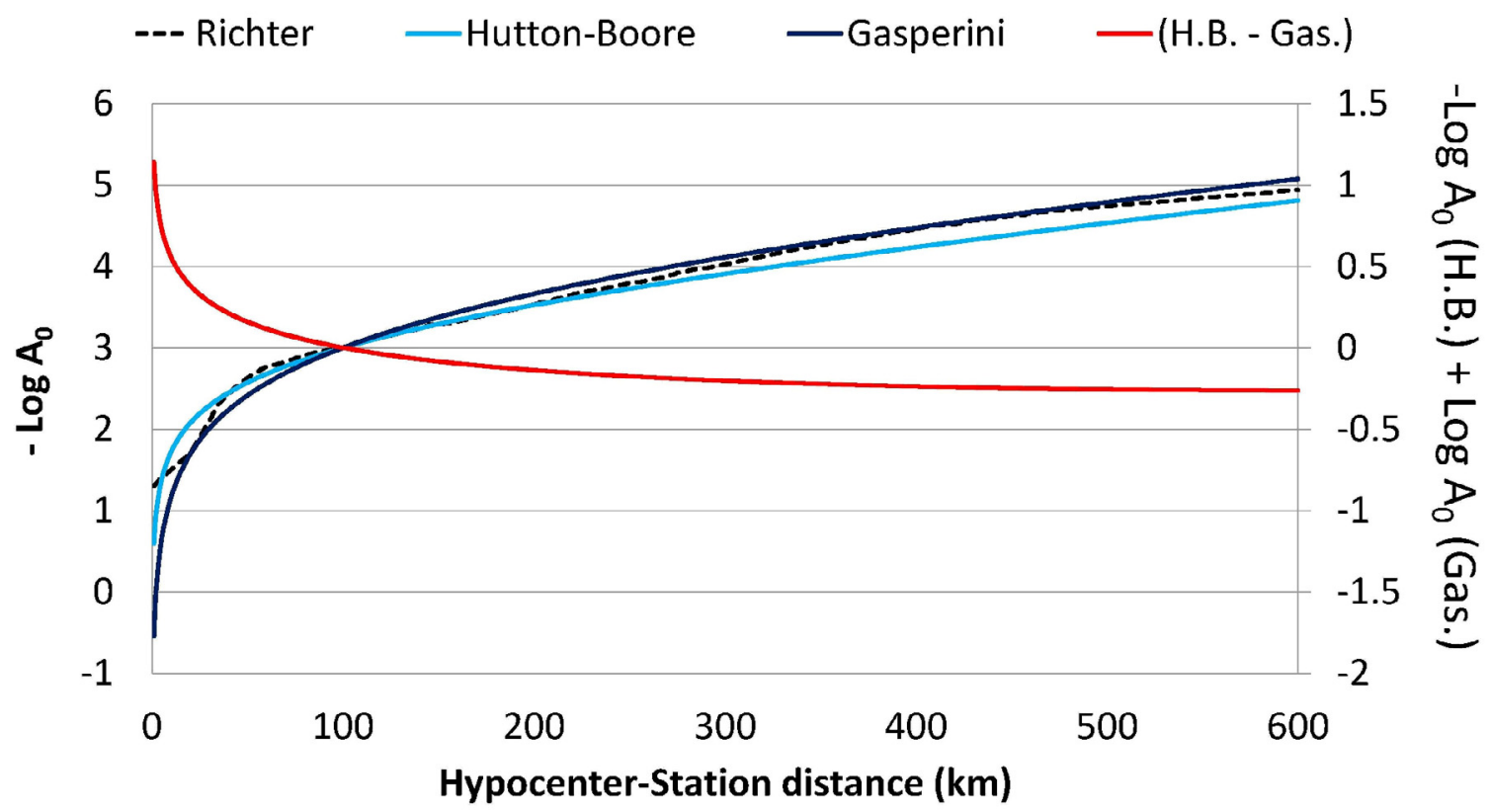

Figure 6. Distance correction (- $\log A_{0}$ ) by Richter (black dashed line), by Hutton and Boore (cyan line), and by Gasperini (dark blue line), and the difference between the Hutton and Boore and the Gasperini corrections (red line, secondary vertical axes).

well the fault geometries reported in the literature for this area, which confirms that the current activity of the northern Apennines thrust systems is controlled by an overall North-South oriented compressive stress field. The extensional event of May 31, 2012, might be related to a secondary extensional stress field.
The test performed by computing the $\mathrm{M}_{\mathrm{L}}$ of 1574 of the seismic sequence again with a different attenuation relation calibrated for Italy shows that: the new $\mathrm{M}_{\mathrm{L}}$ values are in good agreement with those released by the INGV seismic surveillance center for $M_{L}>3.5$. For smaller magnitudes, the Hutton-Boore relation gives greater magnitudes. 
Acknowledgements. We would like to thank all the people on duty at the $24 \mathrm{hr}$ INGV seismic center during the seismic sequence and all the colleagues that installed the real-time temporary seismic stations. We also thank the reviewers for their useful comments. Some Figures were made using the Generic Mapping Tools version 4.2.1 (www.soest.hawaii.edu/gmt).

\section{References}

Amato, A., and F.M. Mele (2008). Performance of the INGV National Seismic Network from 1997 to 2007, Annals of Geophysics, $51(2 / 3)$, 417-431.

Boccaletti, M., G. Corti and L. Martelli (2011). Recent and active tectonics of the external zone of the Northern Apennines (Italy), Int. J. Earth Sci., 100, 1331-1348; doi:10.1007/ s00531-010-0545-y.

Carminati, E., and L. Vadacca (2010). Two and three dimensional numerical simulations of the stress field at the thrust front of the Northern Apennines, Italy, J. Geophys. Res., 115, B12425; doi:10.1029/2010JB007870.

Devoti, R., G. Pietrantonio, A. Pisani, F. Riguzzi and E. Serpelloni (2010). Present day kinematics of Italy, J. Virtual Explorer, 36; doi:10.3809/jvirtex.2009.00237.

Dreger, D.S., and D.V. Helmberger (1993). Determination of source parameters at regional distances with 3-component sparse network data, J. Geophys. Res., 98, 8107-8125.

Gasperini, P. (2002). Local magnitude revaluation for recent Italian earthquakes (1981-1996), J. Seismol., 6 (4), 503-524.

Hutton, L.K. and M. Boore (1987), The $\mathrm{M}_{\mathrm{L}}$ scale in southern California, B. Seismol. Soc. Am., 77, 2074-2094.

Marzorati, S., S. Carannante, M. Cattaneo, E. D'Alema, M. Frapiccini, C. Ladina, G. Monachesi and D. Spallarossa (2012). Automated control procedures and first results from the temporary seismic monitoring of the $2012 \mathrm{Emi}-$ lia sequence, Annals of Geophysics, 55 (4); doi:10.4401/ ag-6116.

Mazza, S., A. Basili, A. Bono, V. Lauciani, A.G. Mandiello, C. Marcocci, F. Mele, S. Pintore, M. Quintiliani, L. Scognamiglio and G. Selvaggi (2012). AIDA - Seismic data acquisition, processing, storage and distribution at the $\mathrm{Na}$ tional Earthquake Center, INGV, Annals of Geophysics, 55 (4); doi:10.4401/ag-6145.

Mele, F., B. Castello, A. Marchetti, C. Marcocci and R. Moro (2007). ISIDe, Italian Seismological Instrumental and parametric DatabasE: una pagina web per interrogare il Bollettino Sismico Italiano, $26^{\circ}$ Convegno Nazionale GNGTS (Roma, 13-15 novembre); http:/ / www2.ogs.trieste.it/ gngts/gngts/ convegniprecedenti/2007/ riassunti/tema-1/ 1-sess-1/ 11-mele.pdf

Montone, P., and M.T. Mariucci (1999). Active stress along the NE external margin of the Apennines: The Ferrara arc, Northern Italy, Geodynamics, 28, 251-265; doi:10.1016/ S0264-3707(98)00041-6.

Montone, P., M.T. Mariucci, S. Pondrelli, and A. Amato (2004). An improved stress map for Italy and surrounding regions (central Mediterranean), J. Geophys. Res., 109, B10410;
doi:10.1029/2003JB002703.

Moretti, M., et al. (2012). Rapid response to the earthquake emergency of May 2012 in the Po Plain, northern Italy, Annals of Geophysics, 55 (4); doi:10.4401/ag-6152.

MPS Working Group (2004). Redazione della mappa di pericolosità sismica prevista dall'Ordinanza PCM 3274 del 20 Marzo 2003, Rapporto Conclusivo per il Dipartimento della Protezione Civile, INGV, Milano-Roma, April 2004, 65 pp. including 5 appendixes; http: / / zonesismiche.mi. ingvit (last accessed September 2009).

Ori, G.G., and P.F. Friend (1984). Sedimentary basins formed and carried piggyback on active thrust sheets, Geology, 12, 475-478; doi:10.1130/0091-7613(1984)12<475:SBFACP $>2.0 . \mathrm{CO} ; 2$.

Pieri, M., and G. Groppi (1981). Subsurface geological structure of the Po Plain, Italy, C.N.R., Progetto Finalizzato Geodinamica, Publ. 414, 1-13.

Pondrelli, S., S. Salimbeni, G. Ekström, A. Morelli, P. Gasperini and G. Vannucci (2006). The Italian CMT dataset from 1977 to the present, Phys. Earth Planet. In., 159 (3/4), 286303; doi:10.1016/j.pepi.2006.07.008.

Rovida A., R. Camassi, P. Gasperini and M. Stucchi, eds. (2011). CPTI11, the 2011 version of the Parametric Catalogue of Italian Earthquakes. Milano/Bologna; http:/ / emidius.mi. ingv.it/CPTI

Scognamiglio, L., E. Tinti and A. Michelini (2009). Real-time determination of seismic moment tensor for the Italian region, B. Seismol. Soc. Am., 99 (4); doi:10.1785/ 0120080104.

Zerbini, S., F. Matonti and C. Doglioni (2006), Crustal movements in northeastern Italy from permanent GPS stations, Geophys. Res. Abstr., 8, Abstract 06257.

\footnotetext{
${ }^{\star}$ Corresponding author: Laura Scognamiglio, Istituto Nazionale di Geofisica e Vulcanologia, Centro Nazionale Terremoti, Roma, Italy; email: laura.scognamiglio@ingv.it.

C 2012 by the Istituto Nazionale di Geofisica e Vulcanologia. All rights reserved.
} 


\section{Appendix A}

Gasperini described the following attenuation relation for Italy [2002]:

$-\log$ Ao $=1.7 \log _{10}(\mathrm{R} / 100)+0.0015(\mathrm{R}-100)+3+\mathrm{Cs}$

where Cs is a station correction, and R is the hypocenter-tostation distance in kilometers. Using (1), we computed the magnitude station corrections for the Emilia sequence.

Table A1 reports the network, the station code, the magnitude station correction Cs, the error of the station correction, the RMS of the component magnitudes used for that station, and the number of observations.

\begin{tabular}{|c|c|c|c|c|c|}
\hline Net & Sta & $\begin{array}{c}\text { Mag } \\
\text { sta-corr }\end{array}$ & Error & RMS & $\begin{array}{c}\text { Number } \\
\text { of data }\end{array}$ \\
\hline SI & ABSI & -0.463 & 0.017 & 0.515 & 902 \\
\hline $\mathrm{NI}$ & ACOM & -0.400 & 0.036 & 0.438 & 152 \\
\hline $\mathrm{NI}$ & AGOR & -0.023 & 0.007 & 0.143 & 404 \\
\hline IV & AOI & 0.149 & 0.024 & 0.181 & 58 \\
\hline IV & APPI & -0.354 & 0.016 & 0.414 & 706 \\
\hline IV & ARCI & 0.519 & 0.074 & 0.531 & 51 \\
\hline IV & ARRO & 0.212 & 0.034 & 0.230 & 46 \\
\hline IV & ARVD & 0.243 & 0.025 & 0.264 & 114 \\
\hline IV & ASOL & -0.508 & 0.104 & 0.572 & 30 \\
\hline IV & ASQU & 0.203 & 0.009 & 0.251 & 802 \\
\hline IV & ASSB & 0.183 & 0.020 & 0.193 & 90 \\
\hline IV & ATBU & -0.243 & 0.019 & 0.283 & 216 \\
\hline IV & ATCA & 0.312 & 0.043 & 0.358 & 68 \\
\hline IV & ATCC & -0.157 & 0.026 & 0.214 & 70 \\
\hline IV & ATMC & -0.014 & 0.010 & 0.112 & 136 \\
\hline IV & ATMI & -0.104 & 0.019 & 0.168 & 78 \\
\hline IV & ATPC & 0.047 & 0.009 & 0.135 & 230 \\
\hline IV & ATPI & 0.165 & 0.015 & 0.179 & 144 \\
\hline IV & ATTE & 0.195 & 0.020 & 0.215 & 118 \\
\hline IV & ATVA & 0.353 & 0.029 & 0.351 & 150 \\
\hline IV & ATVO & 0.059 & 0.009 & 0.129 & 214 \\
\hline IV & BADI & 0.110 & 0.012 & 0.144 & 144 \\
\hline IV & BDI & 0.091 & 0.005 & 0.169 & 1114 \\
\hline IV & ВОВ & -0.152 & 0.033 & 0.633 & 360 \\
\hline SI & BOSI & -0.699 & 0.077 & 0.742 & 92 \\
\hline IV & BRIS & 0.409 & 0.022 & 0.480 & 460 \\
\hline IV & BRMO & 0.033 & 0.008 & 0.205 & 666 \\
\hline IV & CAFI & 0.297 & 0.015 & 0.304 & 388 \\
\hline IV & CASP & 0.386 & 0.029 & 0.402 & 198 \\
\hline
\end{tabular}

\begin{tabular}{|c|c|c|c|c|c|}
\hline Net & Sta & $\begin{array}{c}\text { Mag } \\
\text { sta-corr }\end{array}$ & Error & RMS & $\begin{array}{l}\text { Number } \\
\text { of data }\end{array}$ \\
\hline IV & CELB & 0.135 & 0.031 & 0.304 & 96 \\
\hline IV & CESI & 0.671 & 0.136 & 0.718 & 28 \\
\hline IV & CESX & 0.084 & 0.021 & 0.115 & 30 \\
\hline NI & CGRP & 0.032 & 0.006 & 0.183 & 1054 \\
\hline IV & CING & 0.195 & 0.037 & 0.257 & 48 \\
\hline IV & CMPO & 0.042 & 0.012 & 0.211 & 309 \\
\hline IV & CNCS & -0.377 & 0.074 & 0.483 & 42 \\
\hline IV & COR1 & -0.314 & 0.073 & 0.377 & 27 \\
\hline IV & CPGN & -0.020 & 0.010 & 0.112 & 120 \\
\hline IV & CRE & 0.145 & 0.023 & 0.191 & 68 \\
\hline IV & CRMI & 0.387 & 0.014 & 0.419 & 841 \\
\hline IV & CRND & -0.193 & 0.046 & 0.281 & 38 \\
\hline IV & CSNT & 0.220 & 0.016 & 0.235 & 204 \\
\hline IV & CTI & -0.380 & 0.022 & 0.447 & 407 \\
\hline IV & CTL8 & -0.090 & 0.015 & 0.383 & 634 \\
\hline IV & ERBM & 0.360 & 0.026 & 0.382 & 213 \\
\hline IV & FDMO & 0.246 & 0.021 & 0.269 & 164 \\
\hline GU & FINB & 0.310 & 0.067 & 0.799 & 142 \\
\hline IV & FIU & 0.171 & 0.011 & 0.279 & 662 \\
\hline IV & FNVD & 0.217 & 0.016 & 0.249 & 227 \\
\hline IV & FRON & 0.035 & 0.016 & 0.122 & 59 \\
\hline IV & FROS & 0.115 & 0.015 & 0.137 & 86 \\
\hline IV & FSSB & -0.110 & 0.014 & 0.200 & 210 \\
\hline IV & FVI & -0.113 & 0.021 & 0.190 & 84 \\
\hline $\mathrm{RF}$ & GEPF & -0.004 & 0.013 & 0.136 & 108 \\
\hline IV & GROG & 0.001 & 0.035 & 0.199 & 32 \\
\hline IV & IMI & -0.198 & 0.035 & 0.283 & 64 \\
\hline IV & IMOL & 0.456 & 0.030 & 0.639 & 461 \\
\hline SI & KOSI & -0.165 & 0.008 & 0.270 & 1144 \\
\hline
\end{tabular}

Table A1 (from top to bottom, and from the right column to the left column; continued on next page). 


\begin{tabular}{|c|c|c|c|c|c|c|c|c|c|c|c|}
\hline Net & Sta & $\begin{array}{c}\text { Mag } \\
\text { sta-corr }\end{array}$ & Error & RMS & $\begin{array}{l}\text { Number } \\
\text { of data }\end{array}$ & Net & Sta & $\begin{array}{c}\text { Mag } \\
\text { sta-corr }\end{array}$ & Error & RMS & $\begin{array}{c}\text { Number } \\
\text { of data }\end{array}$ \\
\hline IV & LEOD & -0.346 & 0.086 & 0.436 & 26 & IV & RSM2 & 0.054 & 0.020 & 0.107 & 30 \\
\hline SL & LJU & -0.568 & 0.084 & 0.603 & 52 & NI & SABO & -0.286 & 0.019 & 0.333 & 312 \\
\hline IV & LNSS & -0.087 & 0.019 & 0.124 & 42 & IV & SACS & 0.292 & 0.026 & 0.295 & 124 \\
\hline IV & MABI & 0.282 & 0.009 & 0.312 & 1099 & IV & SALO & -0.181 & 0.009 & 0.310 & 1238 \\
\hline IV & MAGA & -0.747 & 0.023 & 0.801 & 1182 & IV & SANR & -0.454 & 0.073 & 0.547 & 56 \\
\hline GU & MAIM & 0.103 & 0.007 & 0.209 & 900 & FR & SAOF & -0.041 & 0.020 & 0.195 & 92 \\
\hline IV & MGAB & 0.042 & 0.006 & 0.088 & 202 & IV & SBPO & 0.261 & 0.021 & 0.379 & 311 \\
\hline IV & MNTV & -0.202 & 0.041 & 0.323 & 62 & IV & SERM & 0.529 & 0.017 & 0.561 & 1093 \\
\hline IV & MODE & -0.368 & 0.025 & 0.443 & 322 & IV & SFI & 0.110 & 0.007 & 0.197 & 875 \\
\hline IV & MOMA & 0.182 & 0.022 & 0.183 & 70 & IV & SMA1 & -0.177 & 0.029 & 0.208 & 52 \\
\hline IV & MONC & -0.399 & 0.087 & 0.443 & 26 & IV & SNTG & 0.103 & 0.016 & 0.143 & 80 \\
\hline SI & MOSI & -0.477 & 0.020 & 0.536 & 753 & IV & SSFR & -0.131 & 0.036 & 0.191 & 28 \\
\hline IV & MPAG & 0.130 & 0.010 & 0.156 & 238 & IV & SSP9 & 0.082 & 0.013 & 0.113 & 80 \\
\hline IV & MSSA & 0.073 & 0.006 & 0.190 & 858 & IV & STAL & -0.320 & 0.014 & 0.371 & 732 \\
\hline IV & MTRZ & -0.025 & 0.008 & 0.173 & 474 & IV & Т0800 & -0.193 & 0.010 & 0.339 & 1085 \\
\hline IV & MURB & -0.167 & 0.019 & 0.212 & 124 & IV & Т0802 & -0.099 & 0.026 & 0.337 & 170 \\
\hline IV & NARO & 0.357 & 0.029 & 0.364 & 154 & IV & T0803 & -0.039 & 0.021 & 0.268 & 165 \\
\hline GU & NEGI & -0.164 & 0.031 & 0.256 & 68 & IV & Т0805 & -0.045 & 0.020 & 0.247 & 154 \\
\hline IV & NOVE & 0.213 & 0.011 & 0.325 & 914 & IV & T0819 & 0.000 & 0.010 & 0.276 & 718 \\
\hline IV & NRCA & 0.083 & 0.034 & 0.299 & 78 & IV & T0820 & -0.001 & 0.012 & 0.258 & 468 \\
\hline IV & OPPE & 0.056 & 0.015 & 0.176 & 142 & IV & Т0821 & 0.348 & 0.018 & 0.369 & 426 \\
\hline IV & PARC & 0.308 & 0.019 & 0.311 & 282 & IV & T0822 & -0.064 & 0.014 & 0.290 & 414 \\
\hline GU & РCP & 0.032 & 0.011 & 0.180 & 260 & IV & T0825 & -0.257 & 0.026 & 0.358 & 192 \\
\hline IV & PESA & -0.045 & 0.015 & 0.140 & 92 & IV & T0826 & -0.081 & 0.020 & 0.279 & 186 \\
\hline IV & PIEI & 0.250 & 0.016 & 0.273 & 288 & IV & TEOL & -0.116 & 0.007 & 0.234 & 1124 \\
\hline IV & PLMA & 0.002 & 0.007 & 0.163 & 576 & IV & TREG & 0.131 & 0.026 & 0.272 & 110 \\
\hline NI & POLC & -0.318 & 0.017 & 0.370 & 462 & IV & TRIF & 0.360 & 0.041 & 0.360 & 76 \\
\hline GU & POPM & 0.127 & 0.007 & 0.209 & 885 & MN & TUE & -0.049 & 0.018 & 0.197 & 114 \\
\hline IV & PRMA & 0.302 & 0.024 & 0.347 & 208 & IV & VARE & -0.047 & 0.023 & 0.249 & 122 \\
\hline IV & PTCC & 0.001 & 0.011 & 0.138 & 146 & NI & VINO & -0.023 & 0.008 & 0.142 & 282 \\
\hline IV & QLNO & 0.185 & 0.018 & 0.231 & 172 & MN & VLC & 0.439 & 0.021 & 0.450 & 446 \\
\hline IV & RAVA & -0.322 & 0.014 & 0.466 & 1093 & IV & VOBA & -0.263 & 0.036 & 0.359 & 102 \\
\hline SI & RISI & -0.524 & 0.025 & 0.563 & 514 & OE & WTTA & -0.176 & 0.026 & 0.304 & 134 \\
\hline GU & RORO & 0.250 & 0.032 & 0.286 & 80 & IV & ZCCA & 0.334 & 0.010 & 0.358 & 1353 \\
\hline SI & ROSI & -0.392 & 0.020 & 0.441 & 508 & IV & ZEN8 & 0.304 & 0.094 & 0.433 & 21 \\
\hline GU & ROTM & -0.695 & 0.128 & 0.787 & 38 & IV & ZOVE & 0.082 & 0.021 & 0.241 & 128 \\
\hline IV & ROVR & -0.228 & 0.010 & 0.351 & 1186 & & & & & & \\
\hline
\end{tabular}

Table A1 (from top to bottom, and from the right column to the left column; continued from previous page). 


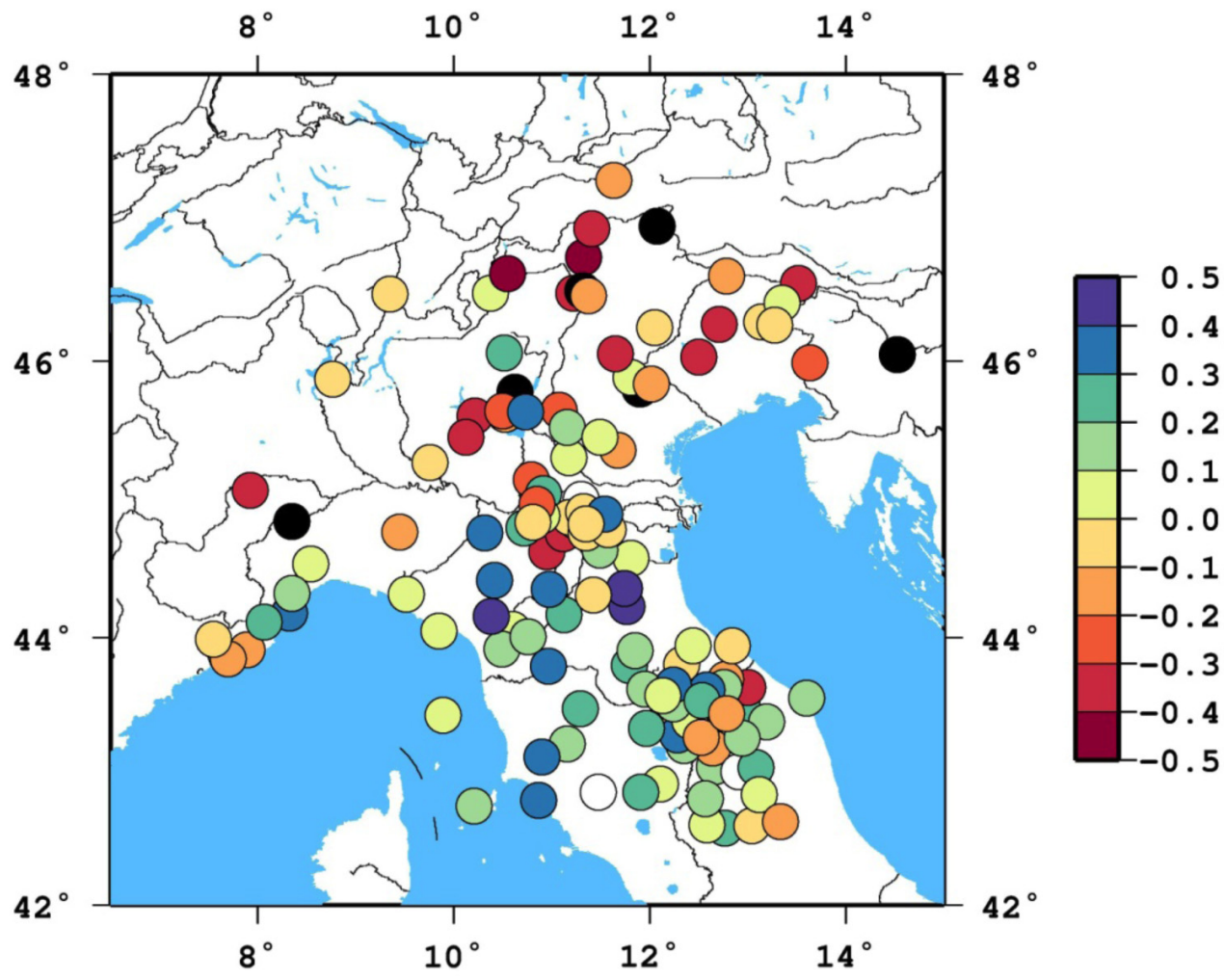

Figure A1. Map of the station corrections for the Emilia sequence. Greenish and blue circles, positive corrections (stations with amplitudes lower than the average); orange-red circles, negative corrections, seen for stations with local amplification or connected to the hypocenters of the sequence by paths crossing low attenuation areas. The negative corrections in stations where the Wood-Anderson amplitudes are, on average, larger than what would be expected applying the simple attenuation law by Gasperini, which is maybe caused by lower attenuation or local amplification and which is prevalent in the northern Italy and north-eastern Alps. The positive corrections are mainly in the northern Apennines and central Italy. The correspondence of this map with the web-based macroseismic intensity map of the main earthquake is strong (INGV, www.haisentitoilterremoto.it). It is worth noting that the magnitude station corrections we have found, should be applied to the Emilia sequence only, or to events with a similar location: the collection of a more general set of data belonging to earthquakes distributed all over the country is a preliminary condition necessary to compute the magnitude station corrections suitable for the entire Italian peninsula.

Table A2 (right). Variance reductions for the 1574 events of the Emilia seismic sequence (May-June 2012) obtained with the attenuation relation by Gasperini [2002] and with the Gasperini relation, plus station corrections (this study). The AIDA system today uses the Hutton-Boore correction for hypocentral distance.

\begin{tabular}{cccc}
\hline Variance & $\begin{array}{c}\text { Variance reduction } \\
\text { with respect to } \\
\text { MLHB }\end{array}$ & $\begin{array}{c}\text { Variance reduction } \\
\text { with respect to } \\
\text { MLG }\end{array}$ \\
\hline MLHB & 7029 & & \\
MLG & 6572 & $6.5 \%$ & \\
MLGC & 2328 & $66.9 \%$ & $64.6 \%$ \\
\hline
\end{tabular}

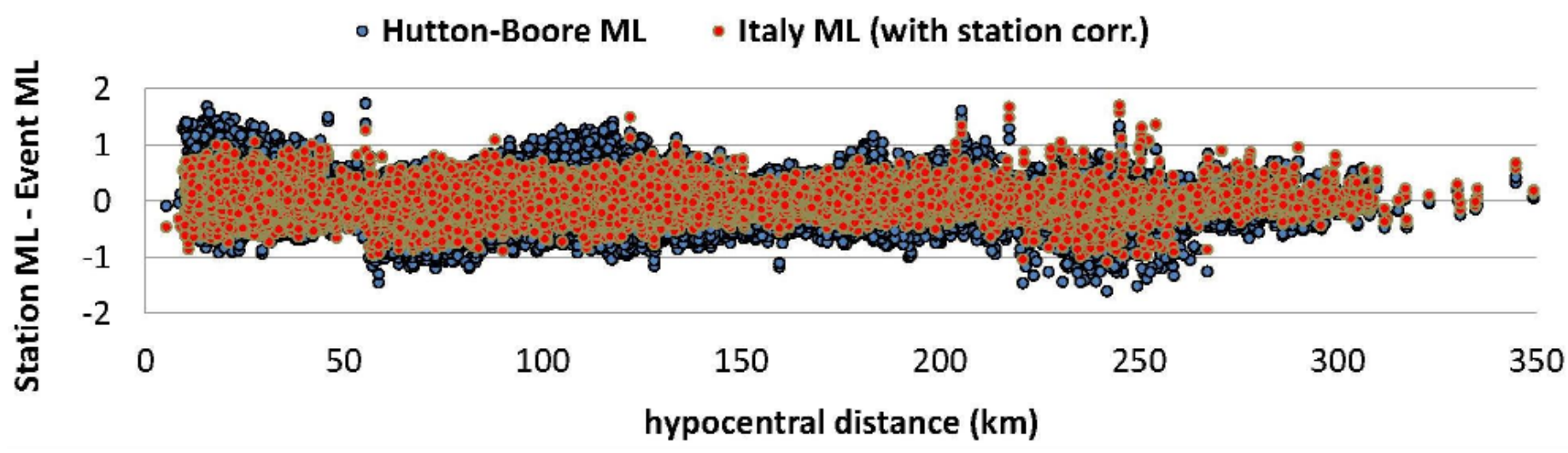

Figure A2. Station magnitude values minus the event magnitudes, computed with the Hutton-Boore relation (blue circles) and with the Gasperini relation for Italy and station corrections (red superimposed circles), as a function of the hypocenter-to-station distance. The distribution of these last magnitudes shows a reduction in the dispersion of the data at all distances. 